\title{
What is $n^{\prime} t$ Doing There?: French Expletive Negation in Comparative Clauses
}

Patrick L. Rich (plrich@fas.harvard.edu)

Harvard University

The normal French preverbal negative particle ne can function as an expletive negative. Expletive ne is essentially limited to three contexts: in subordinate clauses following some verbs (e.g. avoir peur 'to be afraid') or subordinators (e.g. à moins que 'unless') with 'negative' or adversative meanings, and in contrastive comparative subordinate clauses (e.g. Luc en veut plus que Thierry n'en a 'Luc wants more of it than Thierry has'). By 'contrastive', I mean that the two compared elements have to differ with respect to the quality that is being compared. Thus, expletive ne does not occur in equatives, except ones that have a matrix negation, which introduces contrast. Finally, normal clausal negation cannot occur in comparative subordinate clauses.

In order to explore what expletive ne is doing synchronically, I conducted a survey of seven native French speakers. Since the survey confirmed that expletive ne is still a part of synchronic French grammar and that it is not obligatory, the immediate question that comes to mind is: if ne really is expletive, what licenses it and why is it there? Many authors have contributed to this debate. Seuren (1984: 109) noted the "intimate relationship of the comparative in English and most other European languages with negation". Similarly, Stassen (1984: 178) mentioned "strong evidence for the claim that, in a number of particle comparatives, an underlying negative element is present", and later claimed that "in French the negative particle ne shows up obligatorily in a comparative clause if that clause contains a finite verb" (1985: 217). Price criticizes this approach, however, and her analysis hinges on the non-negativity of ne. Instead, she proposes that it is a marker of comparison, and that it serves, for example, to disambiguate equatives from contrastive comparatives (1990: 69).

Wurff (1999) argues that there is a universal tendency in languages to make the complement clause of adversative predicates negative, and that this is due to the fact that the semantics of the licensers entail the negation of the proposition that they embed. Thus, he says, including a negation (expletive or otherwise) gives a closer match between meaning and syntax. He proposes the following templates for licensers and nonlincensers of expletive negation, respectively: $V$ that not $X$, not $V$ that $X$. He argues, following Espinal (1991), that an adversative V l-selects a CP. The C head then l-selects a NegP. In SpecNegP, there is a non-negative (i.e. formally [- NEG]) truth value operator, which marks the clause as having a non-positive truth value and can bind NPIs. Finally, in $\mathrm{Neg}^{0}$ is a [+ NEG] negative head. Assuming the Neg-Criterion of Haegeman (1995), expletive negation is uninterpretable because the truth value operator is not negative.

For this analysis, I argue (contra Price) that French comparatives do contain a semantic negation. Following Heim (2001), I am assuming the type $\langle d$, et $\rangle$ denotation for gradable adjectives in French: $\llbracket \mathrm{ADJ}_{g r} \rrbracket=\lambda d \lambda x . x$ is ADJ $g r$ to degree $d$. I assume the syntax of the comparative proposed by Bresnan (1973), as it makes my proposal more transparent. This is not a crucial assumption, however. Contra Schwarzschild (2008), I argue that the comparative morpheme plus should introduce the semantic negation, as opposed to putting a (sometimes covert) negative operator somewhere downstairs. I propose that 
the comparative operator is a lambda abstraction over a degree in the subordinate clause, and thus that the $\mathrm{CP}$ that must combine with $\mathrm{Deg}^{0}$ denotes a property of degrees (i.e. a function of type $\langle d, t\rangle)$. I ignore the copula and than particles, under the assumption that they are either vacuous or denote the identity function. Here is my proposed denotation

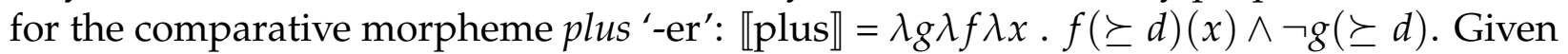
this, the denotations for moins 'less' and aussi 'as' follow naturally: \moins $\rrbracket=\lambda g \lambda f \lambda x$. $f(\preceq d)(x) \wedge \neg g(\preceq d)$, \aussi $=\lambda g \lambda f \lambda x . f(\succeq d)(x) \wedge g(\succeq d)$.

Because of the semantic negation in -er and less, which entails the negation of their complement clauses, they both l-select the than-particle, which l-selects a NegP with the truth value operator in its Spec position and a negative head. The as morpheme does not contain a semantic negation, and occurs with the normal complementizer que. On the one hand, this explains why clausal negation can occur in the subordinate clause of equatives: they embed 'regular' CPs which may or may not contain a (clausal negating) NegP. On the other hand, it explains why clausal negation cannot occur with comparatives, because the SpecNegP position is filled by the truth value operator, blocking clausal negation.

In more recent work (that I presented in my poster at the LSA), I came up with an alternative analysis of expletive negation in French comparatives. For this analysis, I assumie Kennedy's syntax for the comparative:

(1)

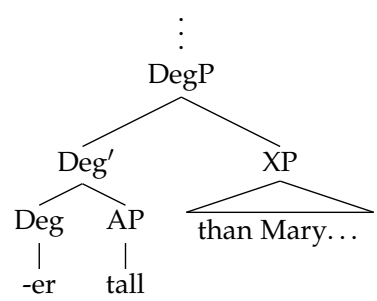

(Kennedy 1997: 118)

Consider the sentence Jean est plus grand que Marie ne l'est 'Jean is bigger than Marie is'. This would have an LF like the following:

(2)

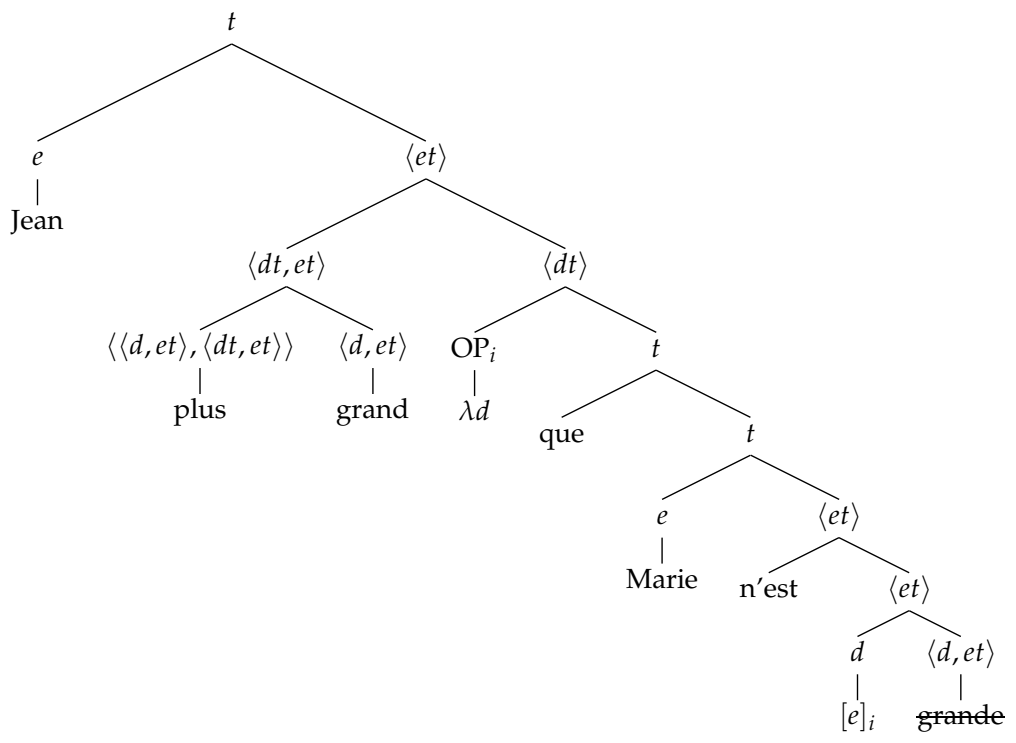


The than-particle is of type $\langle t, t\rangle$ and carries a semantic negation.

Crucially, I am arguing that there are two homophonous complementizers in French: the than-particle and the normal that complementizer. Expletive ne enters into an agreement relationship with the than-particle, thus receiving a concordal interpretation. Here are the denotations that correspond to the LF in (2):

(3) $\quad$ plus $\rrbracket=\lambda f \lambda g \lambda x \cdot f(\succeq d)(x) \wedge g(\succeq d)$

(4) $\llbracket$ grand $\rrbracket=\lambda d \lambda x \cdot G(d)(x)$

$(\equiv x$ is $G$ to degree $d$ )

(5) $\llbracket \mathrm{OP}_{i} \rrbracket$ is a lambda abstraction over a degree in the comparative clause.

(6) $\llbracket$ que $_{\text {than }} \rrbracket=\lambda p \cdot \neg p$

Here is a derivation to clarify what this analysis predicts:

(7)

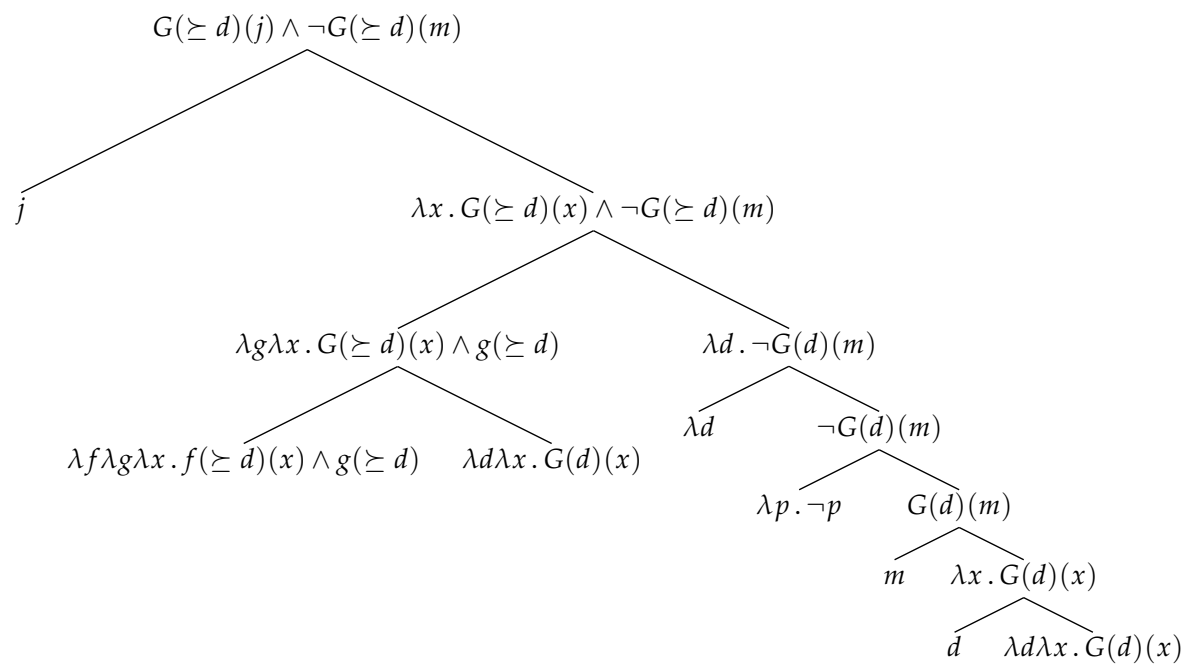

Given this, the question remains of what licenses $q u e_{t h a n}$ as opposed to $q u e_{\text {that }}$. I propose that there is a restriction on -er and less, which is absent from as.

(8) $\llbracket$ plus $\rrbracket=\lambda f \lambda g \lambda x: \neg \exists d(f(d)(x)=g(d)) \cdot f(\succeq d)(x) \wedge g(\succeq d)$

(9) $\llbracket$ moins $\rrbracket=\lambda f \lambda g \lambda x: \neg \exists d(f(d)(x)=g(d)) . f(\preceq d)(x) \wedge g(\preceq d)$

(10) $\llbracket$ aussi $\rrbracket=\lambda f \lambda g \lambda x . f(\succeq d)(x) \wedge g(\succeq d)$

Thus, if que that were used with -er or less, the derivation would crash at the DegP node.

This also accounts for why pas is ruled out in these contexts. The double semantic negation of normal clausal negation and que than would result in the same presupposition failure as the example just discussed using $q u e_{\text {that }}$. Moreover, this explains why expletive negation is ruled out in equatives with a positive matrix (i.e. que that is used, and thus expletive ne isn't licensed), and accounts for why equatives can have normal clausal negation in the comparative clause (i.e. there is no restriction on the equative morpheme, so clausal negation can appear as it would in any other embedded clause).

There are still a few outstanding issues with this analysis. First, some equatives can have expletive negation in the subordinate clause, but only those with a negative matrix. I have accounted for this by saying that they are reconstructed as less comparatives by 
speakers who do this. In that case, my analysis would predict that clausal negation can't appear in an equative with a negative matrix for those speakers, which is not the case. Second, my analysis with the restriction on -er and less seems to make no distinction between cases where the downstairs negation isn't present (i.e. "ungrammatical" examples) and where a given comparative simply has a truth value of o. Finally, I still need to look at the other two contexts where expletive negation occurs with adversatives and the subjunctive. As I look at that, I need to determine whether these cases are the same phenomenon or something different.

\section{References}

Bresnan, J. (1973). Syntax of the Comparative Clause Construction in English. Linguistic Inquiry 4:3. 275-343.

Espinal, M. T. (1991). On Expletive Negation: Some Remarks with regard to Catalan. Lingvisticx Investigationes 15:1. 41-66.

Haegeman, L. (1995). The Syntax of Negation. Cambridge: Cambridge University Press.

Kennedy, C. (1997). Projecting the Adjective: The Syntax and Semantics of Gradability and Comparison. Doctoral dissertation, University of California, Santa Cruz.

Pinkham, J. (1982). The Formation of Comparative Clauses in French and English. Doctoral dissertation, Indiana University, Bloomington.

Price, S. (1990). Comparative Constructions in Spanish and French Syntax. New York: Routledge.

Schwarzschild, R. (2008). The Semantics of Comparatives and Other Degree Constructions. Language and Linguistics Compass 2:2. 308-331.

Seuren, P. A. M. (1984). The Comparative Revisited. Journal of Semantics 3. 109-141.

Stassen, L. (1984). The Comparative Compared. Journal of Semantics 3. 143-182.

- (1985). Comparison and Universal Grammar. Oxford: Basil Blackwell.

Wurff, W. van der (1999). On Expletive Negation with Adversative Predicates in the History of English. In I. Tieken-Boon van Ostade, G. Tottie, and W. van der Wurff (eds.) Negation in the History of English. Berlin: Mouton de Gruyter. 295-327. 